\title{
7-Ketocholesterol Upregulates Interleukin-6 via Mechanisms That Are Distinct from Those of Tumor Necrosis Factor- $\alpha$, in Vascular Smooth Muscle Cells
}

\author{
Si-Chan Sung ${ }^{a}$ Koanhoi Kim ${ }^{b}$ Kyeong-Ah Lee ${ }^{b}$ Kyung-Ha Choi ${ }^{b}$ Sun-Mi Kim ${ }^{b}$ \\ Yong-Hae Son $^{b}$ Yu-Seok Moon ${ }^{c}$ Seong-Kug Eo ${ }^{d}$ Byung-Yong Rhim ${ }^{b}$

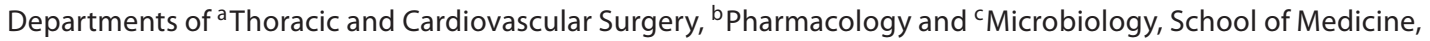 \\ Pusan National University, Busan, and ' Laboratory of Microbiology, College of Veterinary Medicine and Bio-Safety \\ Research Institute, Chonbuk National University, Jeonju, Korea
}

\section{Key Words}

Interleukin-6 · 7-Ketocholesterol · Tumor necrosis factor •

Vascular smooth muscle cell

\begin{abstract}
This study investigated the effects of 7-ketocholesterol on interleukin (IL)-6 expression in vascular smooth muscle cells (VSMC). Among the $7 \mathrm{IL}$ examined, only IL- 6 transcript was increased by 7-ketocholesterol treatment in human aorta smooth muscle cells. IL-6 transcripts increased up to $24 \mathrm{~h}$ after treatment with 7-ketocholesterol, and this effect was profoundly repressed by treatment with p38 MAPK inhibitors and to a lesser extent JNK inhibitors. $7 \alpha$-Hydroxycholesterol, 27-hydroxycholesterol or cholesterol, however, did not induce IL- 6 expression. Mechanisms of IL- 6 induction by 7ketocholesterol were investigated in comparison with tumor necrosis factor (TNF)- $\alpha$. Whereas TNF- $\alpha$ activated IL- 6 promoter, which was impaired by $\mathrm{p} 38$ MAPK inhibitors or by mutation in the NF-кB-binding site within the promoter region, 7-ketocholesterol did not affect IL-6 promoter activity. Instead, this oxysterol slowed degradation of IL- 6 mRNA and increased the amount of cytoplasmic HuR. 7-ketocholesterol significantly increased the amount of intracellular IL- 6 protein in the presence of brefeldin A. 7-Ketocholesterol also enhanced IL- 6 release from VSMC. IL- 6 release by 7-ketocholesterol, although significant, was not as remarkable as that
\end{abstract}

induced by TNF- $\alpha$. These data suggest that 7-ketocholesterol upregulates IL- 6 via mechanisms distinct from TNF- $\alpha$ and contributes to the intra- and extracellular IL- 6 deposits within the vasculature.

Copyright $\odot 2008$ S. Karger AG, Basel

\section{Introduction}

Oxysterols, metabolites of cholesterol, are present in atherosclerotic plaques. According to previous studies, the most abundant oxysterol in human lesions is 27-hydroxycholesterol. Other abundant oxysterols found in these lesions are $7 \alpha$-hydroxycholesterol, 7-ketocholesterol and 7 $\beta$-hydroxycholesterol [1-3]. Since certain oxysterols exhibit more potent atherogenic cellular effects than cholesterol by itself, in some animal and in vitro models, they are believed to play an active role in plaque development $[1,4]$. In vitro, certain oxysterols perturbe several aspects of cellular cholesterol homeostasis, impair vascular reactivity, cause cytotoxicity and induce apoptosis [1]. Despite extensive studies on the cellular effects of oxysterols, it has not been reported whether oxysterols can influence expression of inflammatory cytokines in vascular smooth muscle cells (VSMC).

\section{S.-C.S. and K.K. contributed equally to this work.}

\section{KARGER}

Fax +4161306 1234 E-Mail karger@karger.ch www.karger.com (c) 2008 S. Karger AG, Basel

$1018-1172 / 09 / 0461-0036 \$ 24.50 / 0$

Accessible online at:

www.karger.com/jvr
Prof. Byung-Yong Rhim

Pusan National University, School of Medicine

Department of Pharmacology

10 Ami-dong 1 ga, Seo-gu, Busan 602-739 (Republic of Korea)

Tel. +82 51240 7966, Fax +82 51244 1036, E-Mail byrhim@pusan.ac.kr 
Findings from animal and clinical studies imply that interleukin-6 (IL-6) can be a risk factor for atherosclerosis $[5,6]$ and is required for plaque inflammation $[7,8]$. Moreover, IL- 6 proteins and mRNAs have been detected in the human arterial wall $[9,10]$. IL-6, however, showed different distributions between normal and diseased arteries. Normal intima present with only cellular deposits. In contrast, intimal thickening and fibrous plaques showed extended intra- and extracellular deposits of IL- 6 [10]. These findings suggest that some local factors may induce synthesis of this cytokine in cells of the atherosclerotic arterial wall. However, it is poorly understood which factors may influence expression of this cytokine in the atherosclerotic lesion.

In the present study, we examined whether oxysterols influence the expression of cytokines in VSMC. Among the oxysterols employed in this study, 7-ketocholesterol, the active constituent of oxidized low-density lipoprotein, increased IL- 6 mRNA and protein levels in human aorta smooth muscle cells. In addition, we also investigated the mechanisms by which 7-ketocholesterol upregulates IL-6 in VSMC.

\section{Methods}

\section{Cell Culture and Reagents}

Human aorta smooth muscle cells (Cambrex, East Rutherford, N.J., USA) and A7r5 rat aorta smooth muscle cells (American Type Culture Collection, Manassas, Va., USA) were maintained as previously described [11]. 7-Ketocholesterol, cholesterol and 27-hydroxycholesterol were purchased from Sigma Chemical Co. (St. Louis, Mo., USA). $7 \alpha$-Hydroxycholesterol was purchased from Steraloids (Newport, R.I., USA). SB203580 and SP600125 were purchased from Calbiochem (La Jolla, Calif., USA). Recombinant TNF- $\alpha$ was purchased from R\&D Systems (Minneapolis, Minn., USA).

Nonquantitative and Quantitative Reverse Transcription

Polymerase Chain Reaction Analysis

Total RNA was extracted from human aorta smooth muscle cells using the RNeasy kit (Qiagen, Valencia, Calif., USA). After reverse transcription (RT), nonquantitative or quantitative polymerase chain reaction (PCR) analysis was carried out. Primers for human IL-6 were 5'-AAAGAGGCACTGGCAGAAAA-3' (forward) and 5'-AAAGCTGCGCAGA ATGAGAT-3' (reverse). For human glyceraldehyde-3-phosphate dehydrogenase (GAPDH), the primers were $5^{\prime}$-GAGTCAACGGATTTGGTCGT-3' (forward) and 5'-TGTGGTCATGAGTCCTTCCA-3' (reverse). PCR amplifications were performed as follows: $5 \mathrm{~min}$ at $94^{\circ} \mathrm{C}$ followed by 30 cycles of PCR $\left(30 \mathrm{~s}\right.$ at $94^{\circ} \mathrm{C}, 30 \mathrm{~s}$ at $55^{\circ} \mathrm{C}$ and $30 \mathrm{~s}$ at $\left.72^{\circ} \mathrm{C}\right)$ and a final extension at $72^{\circ} \mathrm{C}$ for $5 \mathrm{~min}$. To ensure that the correct sequences had been amplified, amplification products were sequenced. Quantitative RT-PCR was performed in triplicate in 384-well plates; each $20-\mu \mathrm{l}$ reaction consisted of $10 \mu \mathrm{l}$ of SYBR
Green PCR Master Mix (Applied Biosystems, Foster City, Calif., USA) and $0.8 \mu$ l each of $10 \mathrm{pM}$ forward primer and reverse primer for IL- 6 and GAPDH. Thermal cycling conditions comprised $50^{\circ} \mathrm{C}$ for $2 \mathrm{~min}, 95^{\circ} \mathrm{C}$ for $10 \mathrm{~min}$ and 40 cycles at $95^{\circ} \mathrm{C}$ for $30 \mathrm{~s}$, $60^{\circ} \mathrm{C}$ for $30 \mathrm{~s}$ and $72^{\circ} \mathrm{C}$ elongation period for $30 \mathrm{~s}$. The sequences of the IL- 6 primers were $5^{\prime}$-TACCCCCAGGAGAAGATTCC3' (forward) and 5'-TTTCAGCCATCTTTGGAAGG-3' (reverse). Primers for GAPDH were 5'-ATGG GGAAGGTGAAGGTCG-3' (forward) and 5'-GGGGTCATTGATGGCAACAATA-3' (reverse). RT-PCR was performed using a Prism 7900 Sequence Detection System and quantitative data were analyzed using the Sequence Detection System software (SDS version 2.0; Applied Biosystems).

Plasmid and Transient Transfection

The plasmid containing a 651-bp fragment of the human IL-6 gene promoter located directly upstream of the transcriptional start site, as well as its mutant constructs, were kindly provided by Dr. Oliver Eickelberg (School of Medicine, University of Giessen, Giessen, Germany) [12]. For reporter gene assays, A7r5 rat aortic smooth muscle cells that are readily transfected with Lipofectamine were used [13]. Transfected cells were exposed to 7-ketocholesterol or TNF- $\alpha$ for the indicated periods. Luciferase activities were measured and normalized to $\beta$-galactosidase activity.

Analysis of Intracellular IL-6

After treatment with 7-ketocholesterol or TNF- $\alpha$, cells were incubated for $5 \mathrm{~h}$ with brefeldin A (500 nM), collected, and washed twice with phosphate-buffered saline (PBS). After incubation for 20 min with $100 \mu$ l of Cytofix/cytoperm solution (BD Biosciences, San Diego, Calif., USA), cells were resuspended in $50 \mu \mathrm{l}$ of phycoerytherin (PE)-conjugated anti-human IL-6 antibody (eBioscience, San Diego, Calif., USA), diluted in PBS (1:50 dilution), and incubated at $4{ }^{\circ} \mathrm{C}$ overnight. After washing with PBS, cells were resuspended in $4 \%$ paraformaldehyde. For each sample, 10,000 cells were acquired on a flow cytometer and the data were analyzed.

\section{ELISA of IL-6}

The cytokine content of the culture supernatant was determined through the use of a commercial plate ELISA kit (Amersham, Little Chalfont, UK), according to the manufacturer's instructions.

\section{Confocal Microscopy of $\mathrm{HuR}$}

Human aorta smooth muscle cells, placed on coverslips, were treated with 7-ketocholesterol or TNF- $\alpha$. Cells were then fixed in $4 \%$ paraformaldehyde in PBS for 15 min and permeabilized with $0.2 \%$ Triton X-100 in PBS for 5 min. After washing in PBS, cells were incubated with $1 \mu \mathrm{g} / \mathrm{ml} \mathrm{HuR}$ antibody (Santa Cruz Biotechnology, Santa Cruz, Calif., USA) in 10\% FBS in PBS. Cells were washed and incubated with Alexa Fluor 488-conjugated antibody. Cells were washed once for $30 \mathrm{~min}$ in PBS containing 10\% FBS and $4 \mu \mathrm{g} / \mathrm{ml}$ Hoechst 33342. Cells were viewed by confocal microscopy.

\section{Statistical Analyses}

Statistical analyses were performed by ANOVA and $\mathrm{p}<0.05$ was considered statistically significant. 


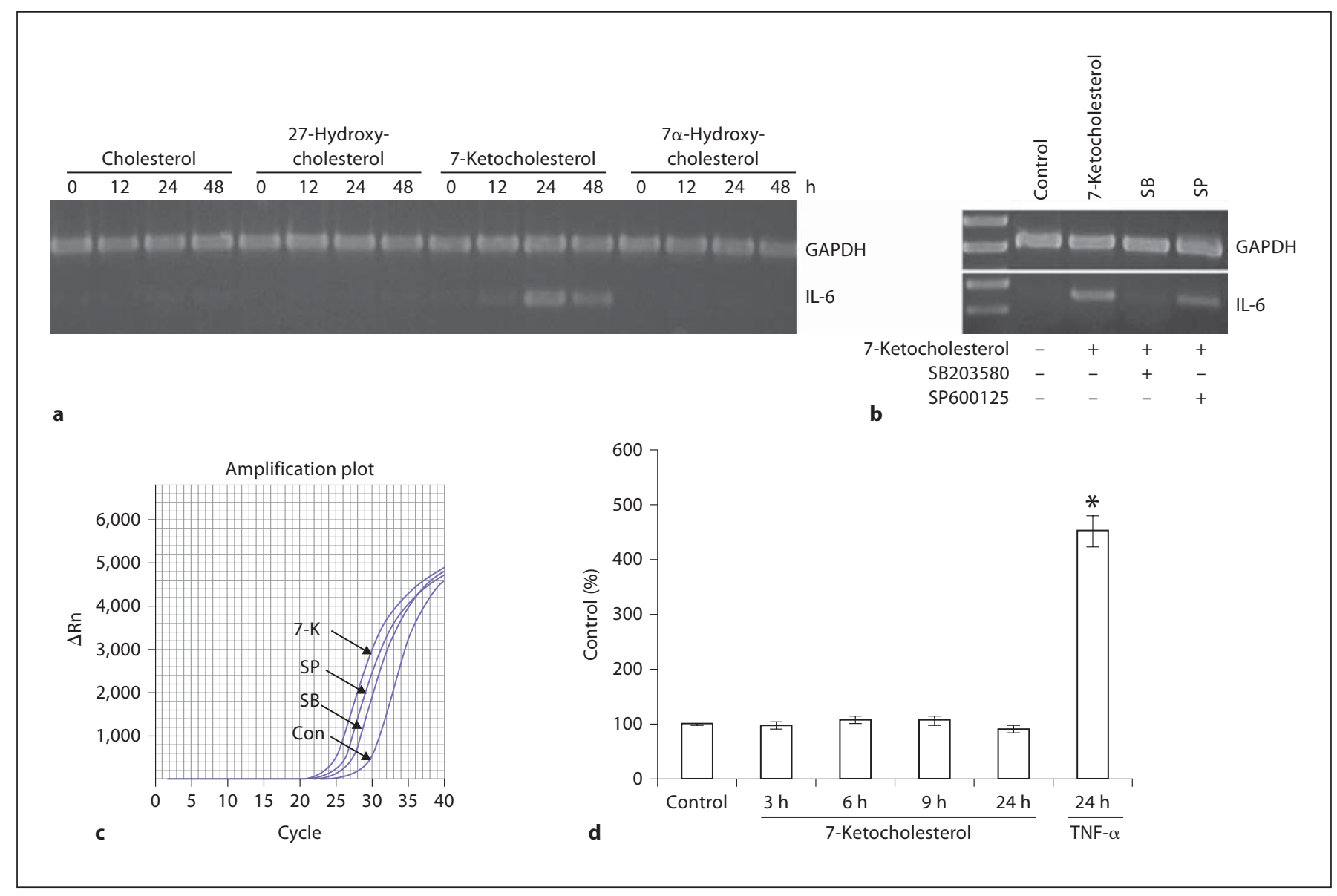

Fig. 1. Effects of 7-ketocholesterol on IL-6 mRNA expression in VSMC. a Human aorta smooth muscle cells were serum starved for $5 \mathrm{~h}$ and treated with cholesterol, 27-hydroxycholesterol, 7-ketocholesterol or $7 \alpha$-hydroxycholesterol at a final concentration of $5 \mu \mathrm{g} / \mathrm{ml}$ for the time periods indicated. RT-PCR were performed using total RNA from each sample, followed by PCR with primers specific for IL- 6 and GAPDH. b, c Human aorta smooth muscle cells were pretreated for $1 \mathrm{~h}$ with SB203580 $(20 \mu \mathrm{M})$ or SP600125 $(20 \mu \mathrm{M})$ prior to exposure to 7-ketocholesterol $(5 \mu \mathrm{g} / \mathrm{ml})$ for $24 \mathrm{~h}$. Nonquantitative RT-PCR (b) and quantitative RT-PCR (c) analy- ses for IL- 6 were performed. d Rat VSMC were transfected with the wild-type pIL-6-Luc651 construct. The transfected cells were stimulated for the time periods indicated with 7-ketocholesterol $(5 \mu \mathrm{g} / \mathrm{ml})$ or TNF- $\alpha(50 \mathrm{ng} / \mathrm{ml})$, and processed for luciferase and $\beta$-galactosidase activities. Luciferase activities obtained without treatment were counted as $100 \%$ and considered the control. Induction of IL- 6 promoter activity in response to treatment was calculated relative to the activity of untreated control cells. Data are expressed as means $\pm \mathrm{SD}$ ( $\mathrm{n}=3$ replicates/group). ${ }^{*} \mathrm{p}<0.01$ vs. control.

\section{Results}

\section{7-Ketocholesterol Increased IL-6 mRNA Levels in}

VSMC, Independent of Promoter Activation

To investigate the effects of oxysterols on cytokine expression in VSMC, serum-starved human aorta smooth muscle cells were exposed to 7-ketocholesterol, $7 \alpha$-hydroxycholesterol, 27-hydroxycholesterol or cholesterol. The transcripts of 7 IL (IL-1 $\alpha$, IL-1 $\beta$, IL-3, IL- 6, IL-11, IL12 and IL-18) were examined by RT-PCR. Figure 1a shows the RT-PCR products of GAPDH and IL-6. These results

indicated that IL-6 was induced by 7-ketocholesterol treatment. The IL- 6 transcript showed a marked increase up to $24 \mathrm{~h}$ after treatment and decreased thereafter. To confirm that the amplified transcript was indeed IL-6, the band was gel purified and sequenced. Expressions of IL-3, IL-1 $\alpha$, IL-1 $\beta$, IL-11, IL-12 and IL-18 were not changed by cholesterol or any of the above oxysterols (data not shown).

To investigate the involvement of p38 mitogen-activated protein kinase (MAPK) and c-Jun-N-terminal kinase/stress-activated protein kinase (JNK) in the induc- 


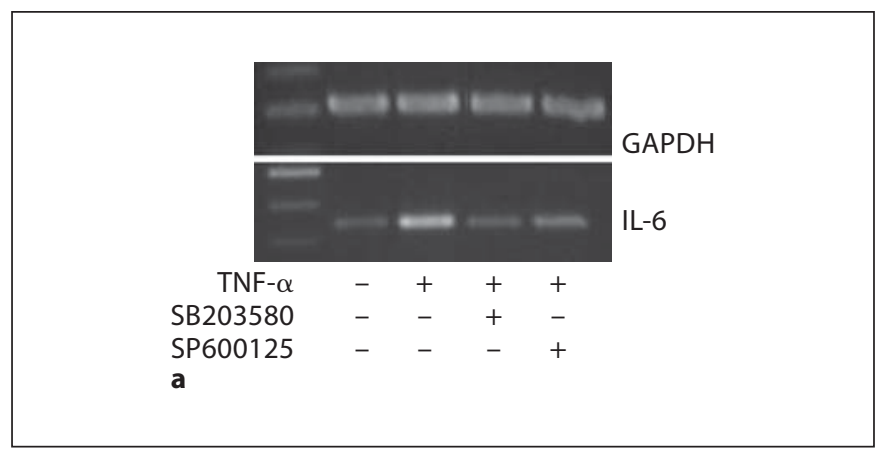

Fig. 2. Mechanisms of IL- 6 regulation by TNF- $\alpha$ in VSMC. a Human aorta smooth muscle cells were pretreated with SB203580 (20 $\mu \mathrm{M})$ or SP600125 $(20 \mu \mathrm{M})$ for $1 \mathrm{~h}$ and then stimulated with TNF$\alpha(50 \mathrm{ng} / \mathrm{ml})$ for $24 \mathrm{~h}$. RT-PCR analysis for IL- 6 was performed and normalized to GAPDH. b Rat VSMC were transfected with pIL-6-Luc651 and either left untreated or treated for $1 \mathrm{~h}$ with SB203580 $(20 \mu \mathrm{M})$ or SP600125 $(20 \mu \mathrm{M})$. Luciferase and $\beta$-galactosidase activities were examined after incubation with or without TNF- $\alpha(50 \mathrm{ng} / \mathrm{ml})$ for $24 \mathrm{~h}$. The luciferase activity was normalized to $\beta$-galactosidase activity. Luciferase activities obtained without treatment were counted as $100 \%$ and considered the control. Luciferase activities of the treated cells were calculated relative to the activity of untreated control cells. Data are expressed as means $\pm \mathrm{SD}$ ( $\mathrm{n}=3$ replicates/group). ${ }^{*} \mathrm{p}<0.01$ vs. control; ${ }^{* *} \mathrm{p}<0.01$ vs. TNF- $\alpha$. c Rat VSMC were transfected with pIL-6luc651 or mutant constructs and stimulated with TNF- $\alpha$ (50 ng/ $\mathrm{ml}$ ) for $24 \mathrm{~h}$. Luciferase activities obtained with the wild-type construct (pIL-6-Luc651) were counted as $100 \%$. Luciferase activities obtained with mutant constructs were expressed as relative to those obtained with the wild-type construct. Data are expressed as means $\pm \mathrm{SD}\left(\mathrm{n}=3\right.$ replicates/group). ${ }^{*} \mathrm{p}<0.05$ vs. pIL-6-Luc651; ** $\mathrm{p}<0.01$ vs. pIL-6-Luc651.

tion of IL-6 by 7-ketocholesterol, specific pharmacological inhibitors were used. Human aorta smooth muscle cells were exposed to 7-ketocholesterol in the presence of SB203580, a p38 MAPK inhibitor, or SP600125, a JNK inhibitor, prior to RT-PCR of IL-6 (fig. 1b). The inhibitors repressed the upregulation of IL- 6 by 7-ketocholesterol. When changes in the IL- 6 transcript were analyzed by quantitative RT-PCR, 7-ketocholesterol elevated IL-6 transcript levels approximately 20 times. However, the induction of IL- 6 by 7-ketocholesterol was decreased by $80 \%$ and 50\% in the presence of SB203580 and SP600125, respectively (fig. 1c). Next, reporter gene assays were carried out to determine whether 7-ketocholesterol influenced IL- 6 promoter activity in parallel with TNF- $\alpha$ (fig. 1d). The IL-6 promoter activity was enhanced by TNF- $\alpha$. Luciferase activity was increased $4-5$ times in response to TNF- $\alpha, 24 \mathrm{~h}$ after treatment. However, treatment with 7-ketocholesterol for 3, 6, 9 or $24 \mathrm{~h}$ did not in-
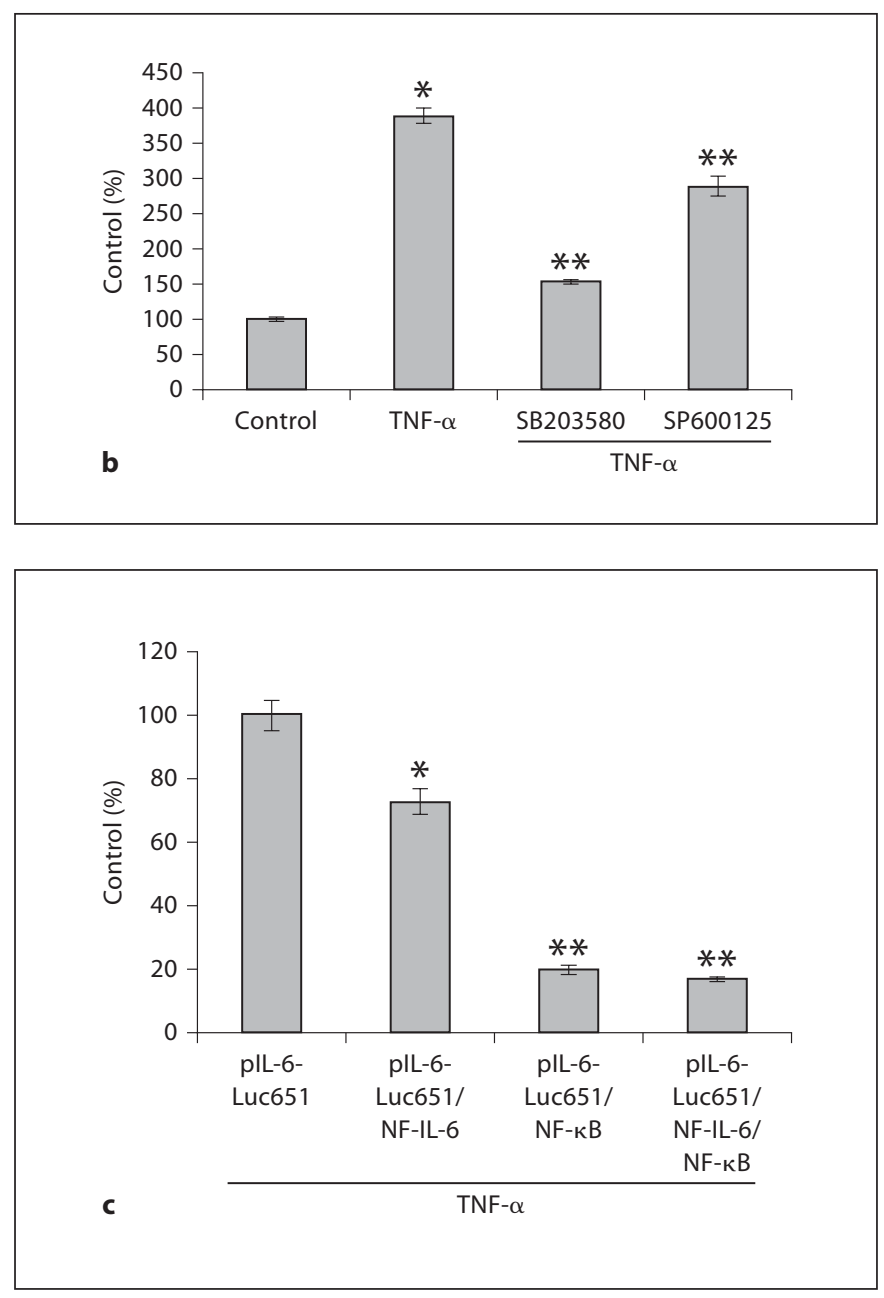

crease luciferase activity driven by the human IL-6 promoter.

\section{Impairment of $p 38$ MAPK or Nuclear Factor- $\kappa B$ \\ Activities Significantly Attenuated IL-6 Induction by \\ TNF- $\alpha$ in VSMC}

It was investigated whether the p38 MAPK or JNK inhibitors affected IL- 6 induction by TNF- $\alpha$, as determined by RT-PCR and reporter gene assays. TNF- $\alpha$-mediated IL- 6 induction was attenuated by the addition of either SB203580 or SP600125 (fig. 2a). Of the 2 inhibitors, SB203580 had a more potent inhibitory effect. Consistent with the results of RT-PCR, the inhibitors influenced IL6 promoter activity in a similar fashion (fig. $2 b$ ). TNF- $\alpha$ activated IL-6 promoter activity by 4 -fold in VSMC. SB203580 and SP600125 decreased TNF- $\alpha$-mediated IL6 promoter activation by $85 \%$ and $30 \%$, respectively. Both nuclear factor (NF)- $\kappa \mathrm{B}$ and CCAAT/enhancer binding 


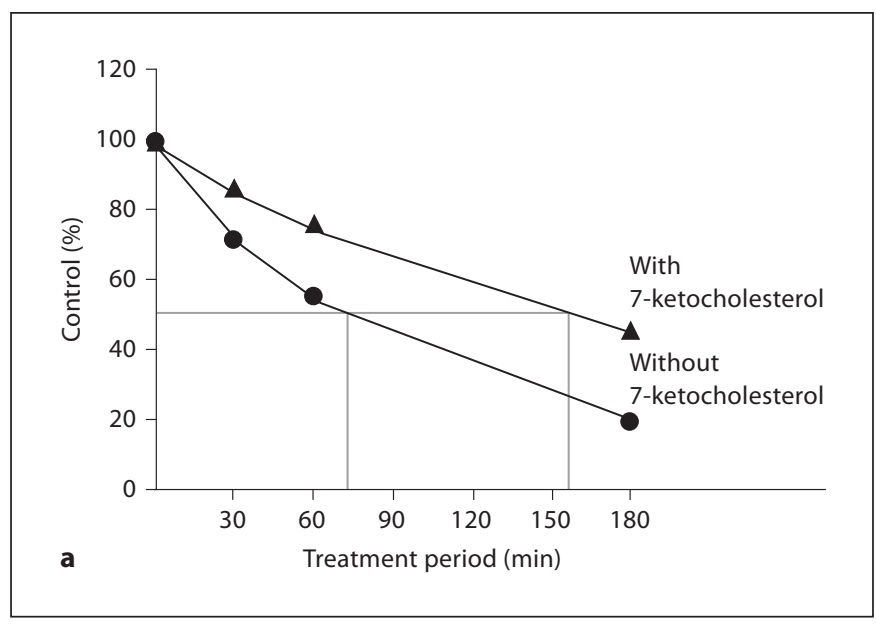

Fig. 3. Effects of 7-ketocholesterol on IL-6 mRNA stability and the cellular distribution of HuR. a Human aorta smooth muscle cells were incubated with or without 7-ketocholesterol ( $5 \mu \mathrm{g} / \mathrm{ml})$. After $24 \mathrm{~h}$, actinomycin D $(10 \mu \mathrm{g} / \mathrm{ml})$ was added and IL- 6 mRNA was analyzed by RT-PCR at the times indicated. Results are presented as the percentage of remaining IL- 6 mRNA at each time point, where $100 \%$ is the level of mRNA at the moment of actinomycin $\mathrm{D}$ addition. Results for each sample were normalized to values obtained for GAPDH. Data are expressed as means of 3 replicates per group. b Human aorta smooth muscle cells were exposed to 7-ketocholesterol $(5 \mu \mathrm{g} / \mathrm{ml})$ for the indicated time periods. Cells were fixed, permeabilized and immunostained for HuR. The fluorescence for HuR was visualized by confocal microscopy. c Human aorta smooth muscle cells were exposed to 7-ketocholesterol $(5 \mu \mathrm{g} / \mathrm{ml})$ for the indicated time periods and cytosolic fractions were prepared. The amount of HuR present in the cytosolic fractions was examined via Western blot analysis in parallel with $\alpha$ tubulin.

protein (C/EBP) seemed to be necessary for maximal activation of IL- 6 promoter by TNF- $\alpha$ in VSMC. Compared with wild type, mutations in the C/EBP- or NF- $\kappa \mathrm{B}-$ binding sites within the promoter region decreased the promoter activity by 20 and 60\%, respectively (fig. 2c). Mutations in both sites decreased TNF- $\alpha$-induced IL- 6 promoter activation by $85 \%$.

\section{7-Ketocholesterol Modified Degradation of IL-6}

$m R N A$ in Conjunction with Cytoplasmic Distribution of $\mathrm{HuR}$

To analyze a possible effect of 7-ketocholesterol on IL6 mRNA stability, we performed experiments using a transcription inhibitor. Actinomycin D was added to VSMC at the end of a 24-hour incubation in the presence or absence of 7-ketocholesterol (fig. 3a). Real-time PCR analysis for IL- 6 after actinomycin D addition showed that the pattern of IL- 6 mRNA degradation changed in
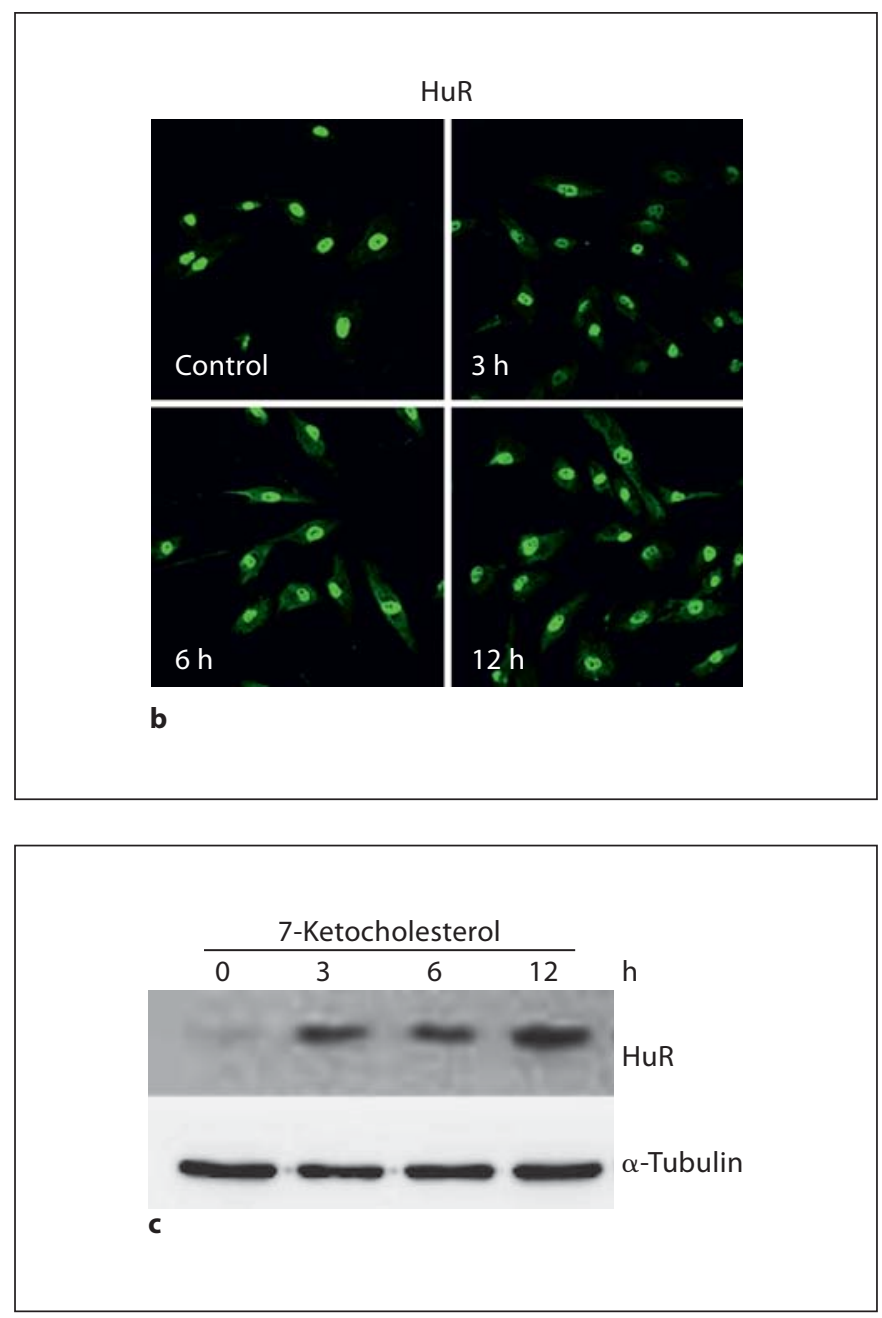

the presence of 7-ketocholesterol. The basal half-life of IL-6 mRNA was relatively short (75 min). However, in the presence of 7-ketocholesterol, the half-life was increased to over $150 \mathrm{~min}$. At $3 \mathrm{~h}$ after addition of actinomycin D, the amount of remaining IL- 6 decreased to $20 \%$ when compared to the reference samples, in the absence of 7ketocholesterol. When compared to the reference samples, the amount of IL- 6 remaining decreased to $43 \%$ in the presence of 7-ketocholesterol. These results suggest that 7-ketocholesterol likely regulates IL-6 at the posttranscriptional level.

Next, the subcellular localization of $\mathrm{HuR}$, which is reportedly involved in mRNA stabilization of cytokines $[14,15]$, was investigated (fig. 3b). Human aorta smooth muscle cells were visualized by confocal microscopy after exposure to 7-ketocholesterol and HuR antibodies. Under basal conditions ( $0 \mathrm{~min})$, a strong fluorescence corresponding to $\mathrm{HuR}$ was seen localized within the nuclei 
along with a faint staining of the cytoplasm. These results indicated that $\mathrm{HuR}$ was mostly localized in the nucleus under these conditions. Treatment with 7-ketocholesterol triggered an increase in cytoplasmic HuR staining as indicated by the appearance of fluorescence outside the nucleus. The maximal density of immunopositive grains in the cytoplasm was observed after $12 \mathrm{~h}$ of treatment with 7-ketocholesterol. The cytoplasmic localization of HuR was also examined via Western blot analysis of cytosolic fractions (fig. 3c). Cytosolic HuR appeared at $3 \mathrm{~h}$ after treatment. A significant amount of cytosolic $\mathrm{HuR}$ was detected at $12 \mathrm{~h}$ after treatment with 7-ketocholesterol.

\section{7-Ketocholesterol Treatment Increased Intracellular}

IL-6 Protein Levels and Enhanced IL-6 Release from VSMC

To investigate whether IL- 6 protein levels were changed in response to 7-ketocholesterol, the amount of intracellular IL-6 was examined. Human aorta smooth muscle cells were treated with 7-ketocholesterol or TNF- $\alpha$ for $24 \mathrm{~h}$. Cells were then incubated with brefeldin A, a potent transport inhibitor that blocks Golgi function and thus blocks IL-6 secretion. Cells were then analyzed by flow cytometry or visualized by confocal microscopy after staining with PE-conjugated monoclonal antibody against human IL-6 (fig. 4a). When compared with control, cells treated with 7-ketocholesterol or TNF- $\alpha$ showed distinct shifts in the distribution of IL-6 fluorescence, indicating an increase in intracellular IL-6. When intracellular IL-6 was visualized, immunofluorescent staining of IL- 6 was evident in VSMC exposed to 7-ketocholesterol or TNF- $\alpha$ (fig. 4b). In contrast, IL-6 immunoreactivity was barely detectable in control VSMC samples. Confocal image analysis showed cytoplasmic staining of IL-6 in the perinuclear region. These data indicated that 7-ketocholesterol treatments increased intracellular IL-6 of human VSMC. Next, it was investigated whether 7-ketocholesterol enhanced secretion of the cytokine. Human aorta smooth muscle cells were incubated for $24 \mathrm{~h}$ with either TNF- $\alpha$ or 7-ketocholesterol, and the level of IL-6 was determined within the culture medium by ELISA (fig. 4c). IL- 6 secretion was significantly increased by 7-ketocholesterol, though not as profoundly as by TNF- $\alpha$. The amount of IL6 within the medium increased from 50 to $100 \mathrm{pg} / \mathrm{ml}$ or to $490 \mathrm{pg} / \mathrm{ml}$ in the presence of 7-ketocholesterol or TNF- $\alpha$, respectively. The secretion of IL- 6 by 7-ketocholesterol, however, did not seem to be augmented by BSA, as the amount of released IL- 6 by cotreatment with 7-ketocholesterol and BSA was comparable to the summation of the secretion observed with each treatment alone.

7-Ketocholesterol Upregulates IL-6 in VSMC

\section{Discussion}

A large number of studies have proposed that oxysterols are involved in the initiation and progression of atherosclerosis by inducing inflammatory cytokines and triggering apoptosis [1]. 7-Ketocholesterol is able to induce death in VSMC and macrophages by the activation of intrinsic [16-20] or receptor-mediated death pathways [11], while 27 -hydroxycholesterol and $7 \alpha$-hydroxycholesterol are reported not to be cytotoxic to cells [21]. In terms of cytokines, 7-ketocholesterol, 25-hydroxycholesterol and $7 \beta$-hydroxycholesterol have been shown to enhance IL-8 expression in human macrophages independently of the Toll-like receptors $[21,22]$. It is, however, unknown whether oxysterols influence IL-6 expression in VSMC. While investigating the effects of oxysterols on cytokine expression in VSMC, we found induction of IL- 6 via 7ketocholesterol treatment at a concentration reported to exhibit trivial cytotoxicity to VSMC $[11,17]$ and within the physiological range found in normocholesterolemic human subjects $[23,24]$. To clarify whether 7 -ketocholesterol was able to increase IL-6 transcript levels via transcriptional activation in VSMC, the effect of 7-ketocholesterol on the IL- 6 promoter was examined using TNF- $\alpha$ as a positive control, which has been reported to increase IL- 6 transcript levels by activating its promoter activity [25]. Consistent with the previous findings, TNF- $\alpha$ increased IL- 6 promoter activity and a mutation at the NF$\kappa \mathrm{B}$-binding site within the promoter region profoundly impaired promoter activation. In contrast, 7-ketocholesterol did not increase luciferase activity driven by the IL6 promoter. It is possible that the promoter construct used in this study might be missing elements responsive to 7-ketocholesterol, if such exist, as the construct contained only a 651-bp fragment of the human IL-6 gene promoter. Thus, identical experiments were carried out with the full-length mouse IL-6 promoter/luciferase reporter gene plasmid designated pmIL-6-luc $(-1,277)$ [26]. The mouse IL- 6 promoter reporter plasmid was also unresponsive to 7-ketocholesterol. The unresponsiveness of the IL- 6 promoter activity indicated that 7-ketocholesterol likely does not affect IL-6 mRNA at the transcriptional level. Measurement of IL-6 mRNA levels under conditions of transcription blockade by actinomycin $\mathrm{D}$ revealed that mRNA degradation was delayed in VSMC that were cultured in the presence of 7-ketocholesterol. These findings suggest that 7-ketocholesterol likely regulates IL- 6 at the posttranscriptional level.

Next, it was investigated whether or not 7-ketocholesterol could influence IL- 6 protein levels in comparison 

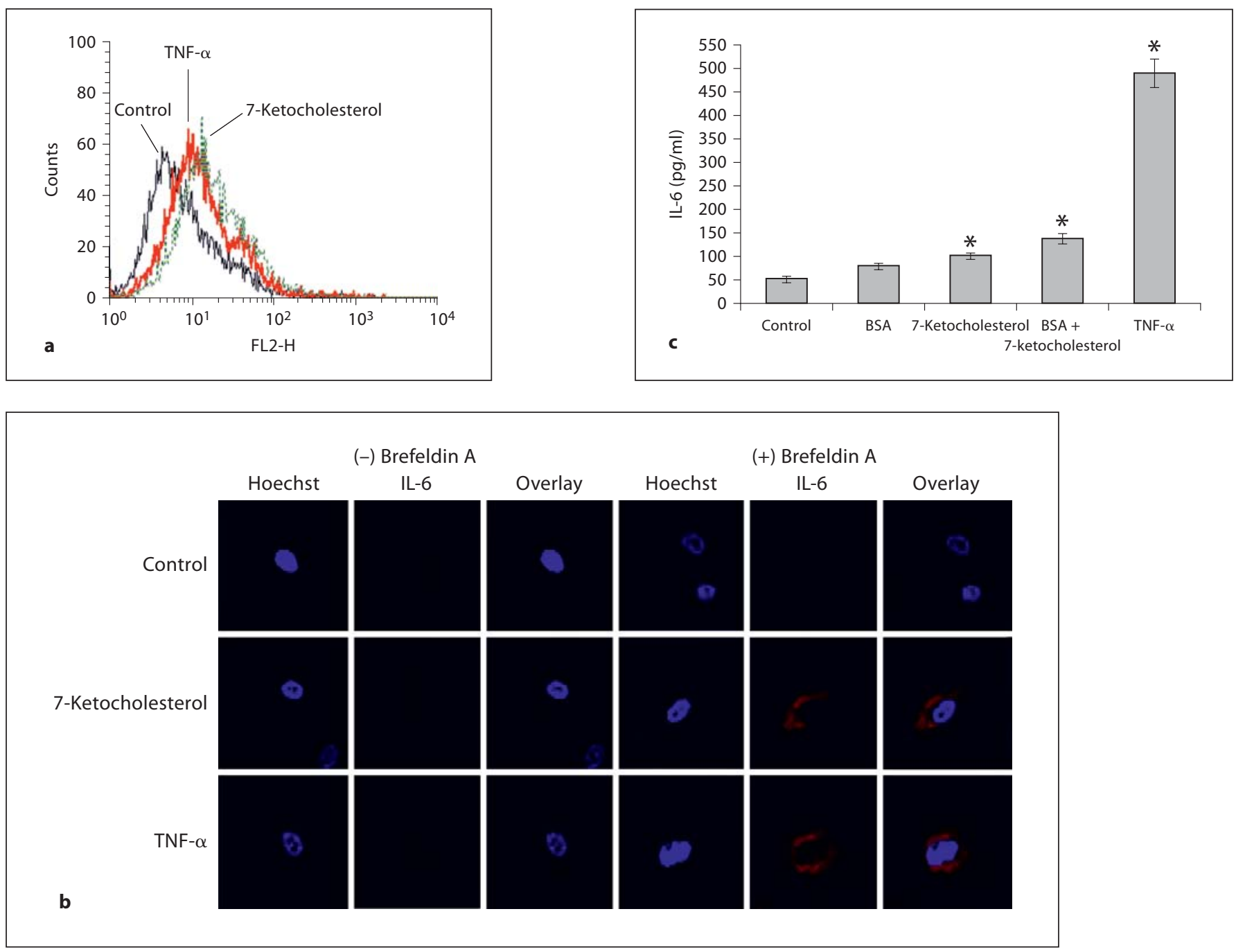

Fig. 4. Effects of 7-ketocholesterol on IL-6 protein levels in VSMC. a Human aorta smooth muscle cells were exposed to 7-ketocholesterol $(5 \mu \mathrm{g} / \mathrm{ml})$ or TNF- $\alpha(50 \mathrm{ng} / \mathrm{ml})$ for $24 \mathrm{~h}$, incubated with brefeldin A for $5 \mathrm{~h}$, and then incubated with PE-conjugated antihuman IL- 6 antibody. The amount of intracellular IL- 6 was assessed by flow cytometry. Histograms represent the fluorescence intensities in untreated control cells or in cells treated with 7-ketocholesterol or TNF- $\alpha$. b Human aorta smooth muscle cells grown on collagen-coated coverslips were treated with 7-ketocholesterol $(5 \mu \mathrm{g} / \mathrm{ml})$ or TNF- $\alpha(50 \mathrm{ng} / \mathrm{ml})$. After incubation with brefeldin A, cells were labeled with PE-conjugated anti-human IL- 6 antibody diluted in PBS (1:50 dilution). After washing, the cells were stained with Hoechst dye in PBS and fixed in $4 \%$ paraformaldehyde. Cells were visualized by confocal microscopy. c Human aorta smooth muscle cells were incubated for $24 \mathrm{~h}$ in the absence (control) or presence of 7-ketocholesterol (5 $\mu \mathrm{g} / \mathrm{ml})$, BSA $(1 \mathrm{mg} / \mathrm{ml})$ or TNF- $\alpha(50 \mathrm{ng} / \mathrm{ml})$. Medium was collected and analyzed for the amount of IL- 6 present. Data are expressed as means $\pm \mathrm{SD}\left(\mathrm{n}=3\right.$ replicates/group). ${ }^{*} \mathrm{p}<0.01$ vs. control. with TNF- $\alpha$, which enhances IL- 6 protein expression and release in VSMC [27]. When intracellular IL-6 was assessed by flow cytometry and confocal microscopy, immunoreactivity of IL- 6 was increased by 7-ketocholesterol treatments. This increase was comparable to that conferred by TNF- $\alpha$. These findings indicated that 7-ketocholesterol treatments could increase IL- 6 protein levels as well as mRNA levels. 7-Ketocolesterol also enhanced IL- 6 release from VSMC, as determined by ELISA. However, this enhanced IL- 6 release was considerably less than that observed with TNF- $\alpha$ treatment. Taken together, the data indicated that 7-ketocholesterol is as effective as TNF- $\alpha$ in terms of increasing intracellular IL- 6 levels, but does not have as strong an effect on IL- 6 release. 
Several RNA-binding proteins have been reported to cause transcript decay or stabilization via binding to $\mathrm{U}$ rich or AU-rich elements present in the $3^{\prime}$-untranslated regions of labile mRNAs [28]. One of the RNA-binding proteins that binds AU-rich elements and promotes transcript stabilization is $\mathrm{HuR}$, which is known to stabilize many mRNAs, including those that encode growth factors, cell division proteins and cytokines. While the precise mechanisms regulating HuR function in mRNA stabilization remain largely unknown, it is apparent that the subcellular localization of $\mathrm{HuR}$ is intimately linked to its function [15]. HuR is predominantly (approximately 90\%) localized in the nuclei of unstimulated cells, and the mRNA-stabilizing influence of HuR requires its translocation to the cytoplasm $[14,15]$. We investigated whether $\mathrm{HuR}$ was translocated in response to 7-ketocholesterol. Confocal microscopy showed that HuR was mainly localized to the nuclei of unstimulated VSMC. Treatment with 7-ketocholesterol led to translocation of HuR into the cytoplasm. This result was also confirmed by Western blot analysis. We also found that 7-ketocholesterol-induced IL-6 mRNA expression was blocked by a p38 MAPK inhibitor, which agrees with a report that p38 MAPK con- tributes to IL- 6 and IL-8 gene expression via stabilization of their mRNAs [29]. These findings indicate that at least 1 mechanism required for IL- 6 mRNA stability is activated by 7-ketocholetserol treatment.

In the present study, we investigated whether oxysterols, known to be present in atherosclerotic plaques, affected the expression of cytokines in VSMC. We found that 7-ketocholesterol could upregulate IL- 6 mRNA via a posttranscriptional mechanism. This study indicated that at subcytotoxic concentrations, 7-ketocholesterol can increase extracellular IL- 6 protein expression by enhancing secretion from VSMC in the diseased vasculature, and that this release of IL- 6 might be involved in the pathogenesis of acute coronary syndrome in patients with hypercholesterolemia via its ability to induce adhesion molecules in the endothelium and proliferation of VSMC [30].

\section{Acknowledgement}

This study was supported by a Medical Research Institute grant (2006-26) from the Pusan National University.

\section{References}

1 Brown AJ, Jessup W: Oxysterols and atherosclerosis. Atherosclerosis 1999;142:1-28.

-2 Garcia-Cruset S, Carpenter KL, Guardiola F, Stein BK, Mitchinson MJ: Oxysterol profiles of normal human arteries, fatty streaks and advanced lesions. Free Radic Res 2001;35: 31-41.

- 3 Vaya J, Aviram M, Mahmood S, Hayek T, Grenadir E, Hoffman A, Milo S: Selective distribution of oxysterols in atherosclerotic lesions and human plasma lipoproteins. Free Radic Res 2001;34:485-497.

4 Olkkonen VM, Lehto M: Oxysterols and oxysterol binding proteins: role in lipid metabolism and atherosclerosis. Ann Med 2004;36:562-572.

5 Biasucci LM, Vitelli A, Liuzzo G, Altamura S, Caligiuri G, Monaco C, Rebuzzi AG, Ciliberto G, Maseri A: Elevated levels of interleukin- 6 in unstable angina. Circulation 1996;94:874-877.

6 Hojo Y, Ikeda U, Katsuki T, Mizuno O, Fukazawa H, Kurosaki K, Fujikawa H, Shimada K: Interleukin 6 expression in coronary circulation after coronary angioplasty as a risk factor for restenosis. Heart 2000;84:83-87.

7 Libby P, Ridker PM, Maseri A: Inflammation and atherosclerosis. Circulation 2002;105: 1135-1143.

7-Ketocholesterol Upregulates IL-6 in VSMC
8 Schieffer B, Selle T, Hilfiker A, HilfikerKleiner D, Grote K, Tietge UJ, Trautwein C, Luchtefeld M, Schmittkamp C, Heeneman S, Daemen MJ, Drexler H: Impact of interleukin- 6 on plaque development and morphology in experimental atherosclerosis. Circulation 2004;110:3493-3500.

-9 Jatta K, Wagsater D, Norgren L, Stenberg B, Sirsjo A: Lipopolysaccharide-induced cytokine and chemokine expression in human carotid lesions. J Vasc Res 2005;42:266-271.

10 Rus HG, Vlaicu R, Niculescu F: Interleukin6 and interleukin- 8 protein and gene expression in human arterial atherosclerotic wall. Atherosclerosis 1996;127:263-271.

-11 Rho MC, Kim YK, Chang JS, Lee HS, Baek JA, Chung MY, Lee HC, Lee HW, Rhim BY, Reidy MA, Kim K: 7-ketocholesterol predisposes human aorta smooth muscle cells to fas-mediated death. J Mol Cell Cardiol 2005; 39:823-832.

12 Eickelberg O, Roth M, Mussmann R, Rudiger JJ, Tamm M, Perruchoud AP, Block LH: Calcium channel blockers activate the interleukin- 6 gene via the transcription factors NF-IL6 and NF- $\kappa B$ in primary human vascular smooth muscle cells. Circulation 1999; 99:2276-2282.
13 Wang JS, Zhang F, Jiang M, Wang MH, Zand BA, Abraham NG, Nasjletti A, LaniadoSchwartzman M: Transfection and functional expression of CYP4A1 and CYP4A2 using bicistronic vectors in vascular cells and tissues. J Pharmacol Exp Ther 2004;311: 913-920.

14 Atasoy U, Watson J, Patel D, Keene JD: ELAV protein $\mathrm{HuA}(\mathrm{HuR})$ can redistribute between nucleus and cytoplasm and is upregulated during serum stimulation and $\mathrm{T}$ cell activation. J Cell Sci 1998;111:3145-3156.

15 Keene JD: Why is Hu where? Shuttling of early-response-gene messenger RNA subsets. Proc Natl Acad Sci USA 1999;96:5-7.

16 Berthier A, Lemaire-Ewing S, Prunet C, Montange T, Vejux A, Pais de Barros JP, Monier S, Gambert P, Lizard G, Neel D: 7ketocholesterol-induced apoptosis. Involvement of several pro-apoptotic but also antiapoptotic calcium-dependent transduction pathways. FEBS J 2005;272:3093-3104.

17 Lizard G, Monier S, Cordelet C, Gesquiere L, Deckert V, Gueldry S, Lagrost L, Gambert P: Characterization and comparison of the mode of cell death, apoptosis versus necrosis, induced by $7 \beta$-hydroxycholesterol and 7-ketocholesterol in the cells of the vascular wall. Arterioscler Thromb Vasc Biol 1999; 19: 1190-1200. 
- 18 Martinet W, De Bie M, Schrijvers DM, De Meyer GR, Herman AG, Kockx MM: 7-ketocholesterol induces protein ubiquitination, myelin figure formation, and light chain 3 processing in vascular smooth muscle cells. Arterioscler Thromb Vasc Biol 2004;24: 2296-2301.

19 Miguet-Alfonsi C, Prunet C, Monier S, Bessede G, Lemaire-Ewing S, Berthier A, Menetrier F, Neel D, Gambert P, Lizard G: Analysis of oxidative processes and of myelin figures formation before and after the loss of mitochondrial transmembrane potential during 7 $\beta$-hydroxycholesterol and 7-ketocholesterol-induced apoptosis: comparison with various pro-apoptotic chemicals. Biochem Pharmacol 2002;64:527-541.

-20 Seye CI, Knaapen MW, Daret D, Desgranges C, Herman AG, Kockx MM, Bult H: 7-ketocholesterol induces reversible cytochrome $\mathrm{c}$ release in smooth muscle cells in absence of mitochondrial swelling. Cardiovasc Res 2004;64:144-153.
21 Lemaire-Ewing S, Prunet C, Montange T, Vejux A, Berthier A, Bessede G, Corcos L, Gambert P, Neel D, Lizard G: Comparison of the cytotoxic, pro-oxidant and pro-inflammatory characteristics of different oxysterols. Cell Biol Toxicol 2005;21:97-114.

-22 Erridge C, Webb DJ, Spickett CM: 25 hydroxycholesterol, $7 \beta$-hydroxycholesterol and 7-ketocholesterol upregulate interleukin-8 expression independently of Toll-like receptor 1,2, 4 or 6 signalling in human macrophages. Free Radic Res 2007;41:260-266.

23 Schroepfer GJ, Jr.: Oxysterols: Modulators of cholesterol metabolism and other processes. Physiol Rev 2000;80:361-554.

24 Sevanian A, Bittolo-Bon G, Cazzolato G Hodis H, Hwang J, Zamburlini A, Maiorino M, Ursini F: LDL- is a lipid hydroperoxideenriched circulating lipoprotein. J Lipid Res 1997;38:419-428.

25 Ammit AJ, Lazaar AL, Irani C, O’Neill GM, Gordon ND, Amrani Y, Penn RB, Panettieri RA, Jr: Tumor necrosis factor- $\alpha$-induced secretion of RANTES and interleukin- 6 from human airway smooth muscle cells: modulation by glucocorticoids and $\beta$-agonists. Am J Respir Cell Mol Biol 2002;26:465-474.
6 Baccam M, Woo SY, Vinson C, Bishop GA: $\mathrm{CD} 40$-mediated transcriptional regulation of the IL- 6 gene in B lymphocytes: involvement of NF- $\kappa$ B , AP-1, and C/EBP. J Immunol 2003;170:3099-3108.

27 Wang Z, Castresana MR, Newman WH: NF$\kappa \mathrm{B}$ is required for TNF- $\alpha$-directed smooth muscle cell migration. FEBS Lett 2001;508: 360-364.

$28 \mathrm{Xu}$ N, Chen CY, Shyu AB: Modulation of the fate of cytoplasmic mRNA by AU-rich elements: key sequence features controlling mRNA deadenylation and decay. Mol Cell Biol 1997; 17:4611-4621.

$>29$ Winzen R, Kracht M, Ritter B, Wilhelm A, Chen CY, Shyu AB, Muller M, Gaestel M, Resch K, Holtmann H: The p38 MAP kinase pathway signals for cytokine-induced mRNA stabilization via map kinase-activated protein kinase 2 and an AU-rich region-targeted mechanism. EMBO J 1999;18:4969-4980.

30 Ikeda U, Ito T, Shimada K: Interleukin-6 and acute coronary syndrome. Clin Cardiol 2001; 24:701-704. 